University of South Florida

DIGITAL COMMONS

Digital Commons @ University of

@ UNIVERSITY OF SOUTH FLORIDA

South Florida

Rehabilitation and Mental Health Counseling

Faculty Publications

Rehabilitation and Mental Health Counseling

2010

\title{
Of Falls and Fractals: My Career with my Mentor, Colleague and Friend, Professor James L. Fozard
}

William D. Kearns

University of South Florida, kearns@usf.edu

Follow this and additional works at: https://digitalcommons.usf.edu/mhs_facpub

\section{Scholar Commons Citation}

Kearns, William D., "Of Falls and Fractals: My Career with my Mentor, Colleague and Friend, Professor James L. Fozard" (2010). Rehabilitation and Mental Health Counseling Faculty Publications. 90.

https://digitalcommons.usf.edu/mhs_facpub/90

This Article is brought to you for free and open access by the Rehabilitation and Mental Health Counseling at Digital Commons @ University of South Florida. It has been accepted for inclusion in Rehabilitation and Mental Health Counseling Faculty Publications by an authorized administrator of Digital Commons @ University of South Florida. For more information, please contact digitalcommons@usf.edu. 


\title{
Of falls and fractals: My career with my mentor, colleague and friend, Professor James L. Fozard
}

\author{
William D. Kearns PhD \\ Department of Aging and Mental Health, \\ Louis de la Parte Florida Mental Health Institute \\ University of South Florida, Tampa, FL 33612, USA \\ E: kearns@fmhi.usf.edu
}

\begin{abstract}
W.D. Kearns. Of falls and fractals: My career with my mentor, colleague and friend, Professor James L. Fozard. Gerontechnology 2010; 9(3):388-396; doi:10.4017/ gt.2010.09.03.010.00 Falls are expensive and often life-changing events. In 2000 there were 2.6 M non-fatal falls that cost the US economy in excess of \$19 B. Fall prediction is an inexact science due in part to the lack of real-time or even near real-time longitudinal monitoring and assessment technologies which can track conditions preceding a fall. Current fall prediction methodologies assess gait and balance parameters at perhaps one or two points in time and attempt to infer future risk. A system for elders that is analogous to the 'black box' flight recorder used in commercial aviation could potentially enhance our knowledge of how fall risks increase over time and what interventions may be successful. This paper describes a system which relies on miniature transponders and fractal mathematics to determine the tortuosity of elders' paths as they traverse open areas within assisted living facilities. It provides background for the development of the concept, especially as it was influenced by earlier research by Professor James L. Fozard. Preliminary data are presented indicating an association between inter-day path variability and the likelihood of falls in elders residing in an assisted living facility.
\end{abstract}

Keywords: wandering, dementia falls, electronic tracking

Falls are expensive adverse events for adults over the age of 65, costing the US economy over $\$ 19$ billion in 2000 and estimates are that it will increase to $\$ 55$ billion by $2020^{1}$. Using data from Medicare records, the estimated direct cost of the 10,300 falls resulting in death in the 2000s was approximately $\$ 176$ million while the 2.6 million non-fatal falls cost $\$ 19$ billion, with almost two thirds going for hospitalization ${ }^{1}$. Data from other studies $^{2,3}$ indicate that approximately a third of all adults over age 65 will experience a fall and that the average cost for a fall including nursing home, emergency room and home health care services is approximately $\$ 20,000$ per incident ${ }^{4}$. The human toll in pain and suffering by the faller and the costs in time and effort by family and informal caregivers are also significant. Hip fractures and traumatic brain injuries resulting from falls are associated with very high mortality rates ${ }^{1}$.

\section{CAuSES AND RISK FACTORS}

The causes of falls and the increased risk for falls are the result of complex interactions among multiple personal and environmental factors including cognitive factors such as the fear of falling ${ }^{5,6}$, and age-related changes in the sensory, physiological, and musculoskeletal systems or medical conditions such as peripheral neuropathy. Stevens' review ${ }^{1, p 294}$ emphasized the frequent research finding that among communitydwelling older adults, the risk of falling is 3 to 4 times higher in people with muscle weakness or gait and balance disorders. A third of documented falls among the elderly are attributed to environmental factors resulting in accidental falls; the remaining two thirds are attributed to personal factors. Stevens $^{1}$ cites the need for improved and more frequent use of gait and balance screening, better medication management (fewer psychoactive medications) and the reduction or 
elimination of home environmental hazards such as poor lighting, unsecured rugs, and of the need for support rails or other assistive hardware in bathrooms and stairways.

\section{Gait, BalanCe AND falls}

Standardized assessments of gait and balance (SGB) measure the body's natural ability to maintain equilibrium under standardized challenges. They are time and labor intensive, expensive to administer and summarize the person's status at one point in time. Accordingly, they may not adequately predict transient changes in gait and balance induced by alterations in medications (especially those with psychoactive properties) or short-term infections.

SGB assessments include stride length, step length, support base, step time, swing time, stance time, single support time, double support time and average velocity measures. Measurements outside a laboratory can be performed by a trained professional using a portable gait mat and recording device. Assessment of static balance includes measures of body sway recorded when a person is standing on one or two legs with eyes closed or open; similarly dynamic balance assessments are made while a person is walking or performing an additional task such as talking on a cell phone. Condron et al. ${ }^{7}$ found that the addition of a secondary task, counting backwards by threes, distinguished a group of 20 elderly persons with a history of falls in the prior 12 months from a group of age peers with no falls. The reported sensitivity and specificity of classifying subjects into the two groups were both 0.8 .

A review by Rubenstein and Josephson ${ }^{8}$ elucidates the multiple factors contributing to falls, which limits the predictive power of any one measure. Hill et al.'s research ${ }^{9}$ helps define the temporal bounds beyond which standardized gait, balance and muscle strength measures would predict fall incidence. Their subjects were 100 communitydwelling women with an average age of 74 years carefully screened to eliminate those with histories of falls, use of canes or other mobility aids, visual or balance problems, and medications or diseases that could increase fall probability. At 12 month followup $49 \%$ had fallen at least once and $23 \%$ more than once with the majority occurring in or around the home. Fear of falling was the one significant predictor $(\mathrm{OR}=2.42)$ of subsequent falls. Hill's extremely rigid screening to eliminate more frail participants may have reduced the relationship between $\mathrm{SGB}$ and muscle strength measures and subsequent falls. In our current research program, we study individuals more frail than Hill's subjects.

Recently researchers ${ }^{10,11}$ have used fractal analytic techniques to reveal new information about gait and balance variability leading to improved fall prediction. A straightforward analysis of variability can sometimes predict fall risk - for instance, Hausdorff et al. ${ }^{3}$ found a relationship between increased stride time variability and increased fall risk in community dwelling elders. Stride time variability also negatively correlated (-0.47) with participants' Mini Mental State Exam scores, a measure used to assist in diagnosing dementia. However, a fractal scaling index of stride times can sometimes detect subtle changes in gait dynamics that variability cannot. For example, Herman et al. ${ }^{11}$ found that while gait variability was not correlated with risk of falls for adults with walking difficulties (not associated with any known disability or chronic condition), fractal scaling index was.

Some gait and balance measures such as decreased stride length, increased double support time and reduced walking, which are adaptive strategies to increase stability, are indirect predictors of falls. Reduced stride length has been found to be a poor fall predictor, but a good indicator of fear of falling ${ }^{6}$. Conversely, increased variability in stride to stride length, stride to stride walking speed and double support time is associated with increased fall risk $^{6}$. Step width, conversely, appears associated with fear of 
falling and falls risk. Probably the best single predictor of falls seems to be stride-to-stride walking speed variability, however, other falls researchers have found that impaired cognitive functioning in dementia, and dementia related wandering are predictive of falls ${ }^{12}$.

\section{GaIt AND MANUAL ReSPONSE TIME}

The links between within-person variability in gait and cognitive deficits extends earlier findings on variability in manual movements and age. It is a truism in gerontology that inter-individual differences increase with age in almost every function which has been studied-reflecting different patterns of experience and interactions with the environment; identical twins are more alike at age 1 than at age 80 . The more controversial issue is whether intra-individual differences in functions increase with age as well. In the area of response latencies for making decisions in both continuous (tracking, walking) and discrete tasks (retrieving information from memory, selective and shared attention), the answer would appear to be "yes". In the 1970s, a group of scientists consisting of Jim Fozard, Nancy Waugh, John Thomas and later Leonard Poon, examined the issue of increasing intra-individual variability as part of a highly productive research program known as 'Mental Performance and Aging ${ }^{13}$. In their researches, they discovered the average time required to retrieve information from sensory, primary, secondary (episodic), and tertiary memory were differentially affected by age. A common feature of their research design was to control for the quality of memory; in addition to examining averages they calculated distributions of latencies by age group, and found relatively longer latencies in successively older cohorts. Fozard and colleagues discovered the distribution of latencies below the median appeared to be very similar across age groups; however, those above the median had higher variability across age. In subsequent work these investigators studied the time required to recall responses to lists of paired associates (ace-boy; cat-dog....) as a function of how well the list was memorized. They found the time to name the response member of the pair that had been correctly recited on previous trials was much longer in older subjects who had mastered fewer of the pairs than was the case for younger subjects who memorized more pairs in the same number of trials. They also found that proactive inhibition played a much greater part in both recall and recognition of items in older age, complementing work by their contemporaries, which investigated age differences in selective and shared attention tasks. The results clearly showed it was harder for older persons to ignore irrelevant stimuli, and therefore they were more influenced by false cueing of target stimuli. A smaller body of research found similar age-related problems occurred in continuous movement tasks (upper limb). So when Fozard and I began looking at movement patterns in frail older persons in 2007, it was only natural that we would focus on intra-individual differences in the spatial (and temporal) dimensions of movement associated with cognitive decline, and on changes in cognitive function associated with medication changes and changes in health. The seminal work by Hausdorff ${ }^{14}$ and others showing greater variability in gait as evidenced in simple walking tasks of old people paralleled earlier findings concerning response latencies and studies of attention in the elderly.

The second line of research that is relevant to our present work is the growing body of work showing that walking and quality of gait which are seemingly automatic in young age require additional cognitive effort in older age ${ }^{15}$. Most of the additional processing involves evaluating environmental information gained through the visual system. Fozard has documented this development in his review of the literature on age-related changes in vision in the first three odd numbered editions of the Birren \& Schaie 'Handbook of the Psychology of Aging ${ }^{16}$. Research on age differences in sensory memory reported by Cerella, Poon and Fozard $^{17}$ reinforced Fozard's impressions 
concerning the importance of this body of research; in these studies a group of six or seven letters is presented for periods of 30200 milliseconds, and the subject reports as many as possible. Since the total time the display is available to the subject is the display time plus the positive afterimage, the advantage of the latter is eliminated by presenting a masking stimulus coincident with the end of the presentation. For all presentation durations, older subjects got fewer letters correct than younger ones. Persons with dementia from a similar study performed in Britain ${ }^{18}$ never achieved more that 1-1.5 letters showing both extreme slowness in assimilating information and likely more response inhibition ${ }^{19}$.

\section{Automated ASSESSMeNT OF MOVEMENT}

The measures of directional variability and movement velocity we have evaluated against SGB measures are derived from research by Kearns et al. ${ }^{20}$, and Kearns, Nams and Fozard ${ }^{21}$ summarized below. A number of methodologies have been used to track persons' movements within buildings. Hayes and colleagues ${ }^{22}$ employed inexpensive passive infrared (PIR) and electromechanical sensors to determine the presence of persons within rooms and were able to detect evidence of cognitive decline which could improve fall risk prediction. However, PIR cannot differentiate individuals by infrared emissions alone, nor can electromechanical sensors on doors, etc. although sophisticated algorithms ${ }^{23}$ have been developed which improve correct identification. PIR and electromechanical sensors together can provide adequate zone level coverage but not individual level tracking, which may suffice for the limited case of an individual alone in a building but is entirely insufficient for tracking large numbers of persons simultaneously ${ }^{24}$. Smart house technologies have used floor pressure sensors to measure gait ${ }^{25}$ and may employ radio frequency identification devices (RFID) to differentiate individuals in congregate settings ${ }^{26}$. RFID allows the differentiation of unlimited numbers of individuals by assigning a unique identifier to each RFID device attached to an individual or their clothing and records the location of the RFID as it passes by sensors positioned at fixed locations. Ultrawideband is a variant of RFID that allows not only the identification but the vector of a transponder to be known, allowing theoretically hundreds of individuals to be tracked at once.

SGB measures' limited ability to predict future falls has been shown by Hill et al. to be due in part to their being obtained at a single point in time ${ }^{9}$. We contend that continuous monitoring of free movement variability and velocity in close temporal proximity to falls may extend understanding of events leading to a fall in much the same manner that the introduction of the 'black box' flight recorder has resulted in improvements in airline safety. For this reason, we automatically assess free movement variability over months.

\section{Preliminary study}

The movement tracking system (MTS) described in this paper was initially developed to quantify wandering behavior associated with dementia. The concept was originally introduced by Kearns and Moore at the federal Agency for Healthcare Research and Quality National Conference on Health Information Technology in April 2006 where it was cited as the most innovative use of Health Information Technology and displayed in Washington, D.C. for Health Information Technology week. The technical evaluation of the system was recently reported by Kearns et al. ${ }^{20,27}$ which showed it was capable of differentiating elders with cognitive disabilities from normal elders based only on their free movements ${ }^{21}$. The results relevant to the present discussion are summarized below.

\section{Subjects}

Fourteen assisted living facility (ALF) residents completed the 30-day protocol; all but 2 of the 14 participants were female. The mean age was $82.2(\mathrm{SD}=9.92)$ and the median was 86.5 years, residents ranged 
from 63 to 93 years of age. One participant was fully ambulatory, 8 used wheelchairs and 5 used a rolling walker. Information was not gathered on past fall history or visual or balance problems in this investigation. One subject volunteered to continue wearing the tag for an extended interval beyond the 30 days of recording to provide information on elder tolerance for wearing the tag.

\section{Apparatus and procedure}

The MTS was a Ubisense Inc. Ultra Wideband radio research pack using wrist worn 'compact tag' transponders measuring $38 \times 39 \times 16.5 \mathrm{~mm}$ and weighing $25 \mathrm{~g}$, and four wall-mounted sensors. A Belkin Inc. Power of Ethernet 100 BaseT switch and 7 shielded category 5e network cables transferred data to a Dell Inspiron model 1501 notebook computer. Ubisense 2.0 software ${ }^{20,27}$ on the computer was used to process and store sensor data. Tags sent signals to four Ubisense 2.0 sensors installed at each corner of an approximately rectangular (25.6 meters by 9.3 meters) common space that interconnected two dormitory wings with an exterior exit and a dining room where all subjects dined; the space contained sofas, tables, comfortable chairs and a television set. Tags were attached by ALF staff by a comfortable wristband after medications and the morning meal and surrendered before retiring. The tags transmitted $x, y$, and $z$ coordinates in meters once every 0.43 seconds when in motion relative to an origin in one corner of the room. Following 30 days of data col-

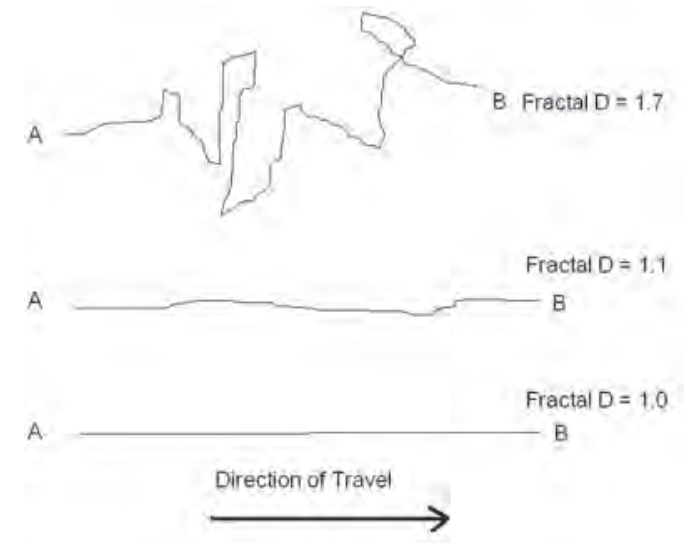

Figure 1. Three hypothetical Fractal $D$ values for walking elders

lection, the Mini Mental State Exam ${ }^{28}$ was administered to each participant.

\section{Results}

After software filtering to remove errant data 854,336 location data points were available for analysis. Location data points were consolidated into paths using the following algorithm: the beginning and ending of a path was defined by tags that did not change position for $60 \mathrm{~s}$. Each participant's path data were blindly analyzed for tortuosity using the Mean Fractal D estimator program ${ }^{29}$. Fractal D (tortuosity) ranges in value from a minimum of 1 , when the line is perfectly straight, to maximum of 2 when the line is so tortuous as to completely cover a plane. Thus, a person that is wandering aimlessly (a random walk) would have a tortuous path and a Fractal D approaching 2.0 (Figure 1).
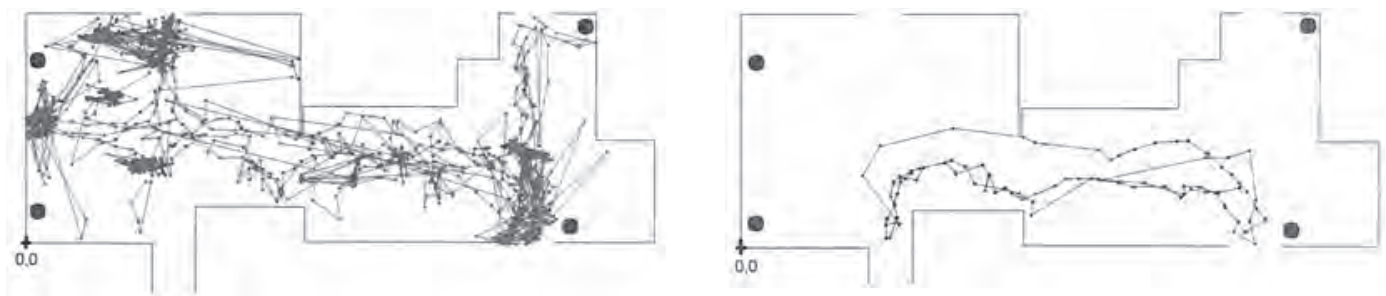

Figure 2. Two hours of raw location data from two subjects recorded at 9 a.m. at the first assisted living facility site. Subject \#10 (left panel) demonstrated a highly variable path and a mean Fractal D of 1.62 and an MMSE of 21 and suffered a hip fracture after wearing the tag for 80 days. Subject \#12 (right panel) followed relatively straighter paths and had a mean Fractal D of only 1.24 and an MMSE of 25. Ovals denote sensor locations 
The median number of data points per participant was 43,397 , and ranged from 3,727 to 230,241 reflecting large individual differences in both time spent in range of the MTS and differences in their total amount of movement (Figure 2). When consolidated into paths they ranged in number from 141 to 1,030 with an average of 530.2 per person. The mean MMSE score was 20.4 $(\mathrm{SD}=4.91)$ and the median was 20.5. A Pearson product-moment correlation coefficient computed between each subject's average Fractal D and their MMSE score was statistically significant $(r=-0.047, p<0.05)$, supporting the primary hypothesis that persons with lower cognitive functioning had more tortuous walking paths.

A serendipitous finding in the study came from the data of two participants who experienced falls during the observation period. We examined the day to day variability in their Fractal D scores prior to their falls. The results show that in comparison to similar persons who did not experience a fall, the variability in the daily Fractal D's for the fallers increased considerably (Figure 3). Although there is significant between-subject variability in day to day Fractal D, the day to day pattern within a particular participant is generally quite consistent. It was this finding
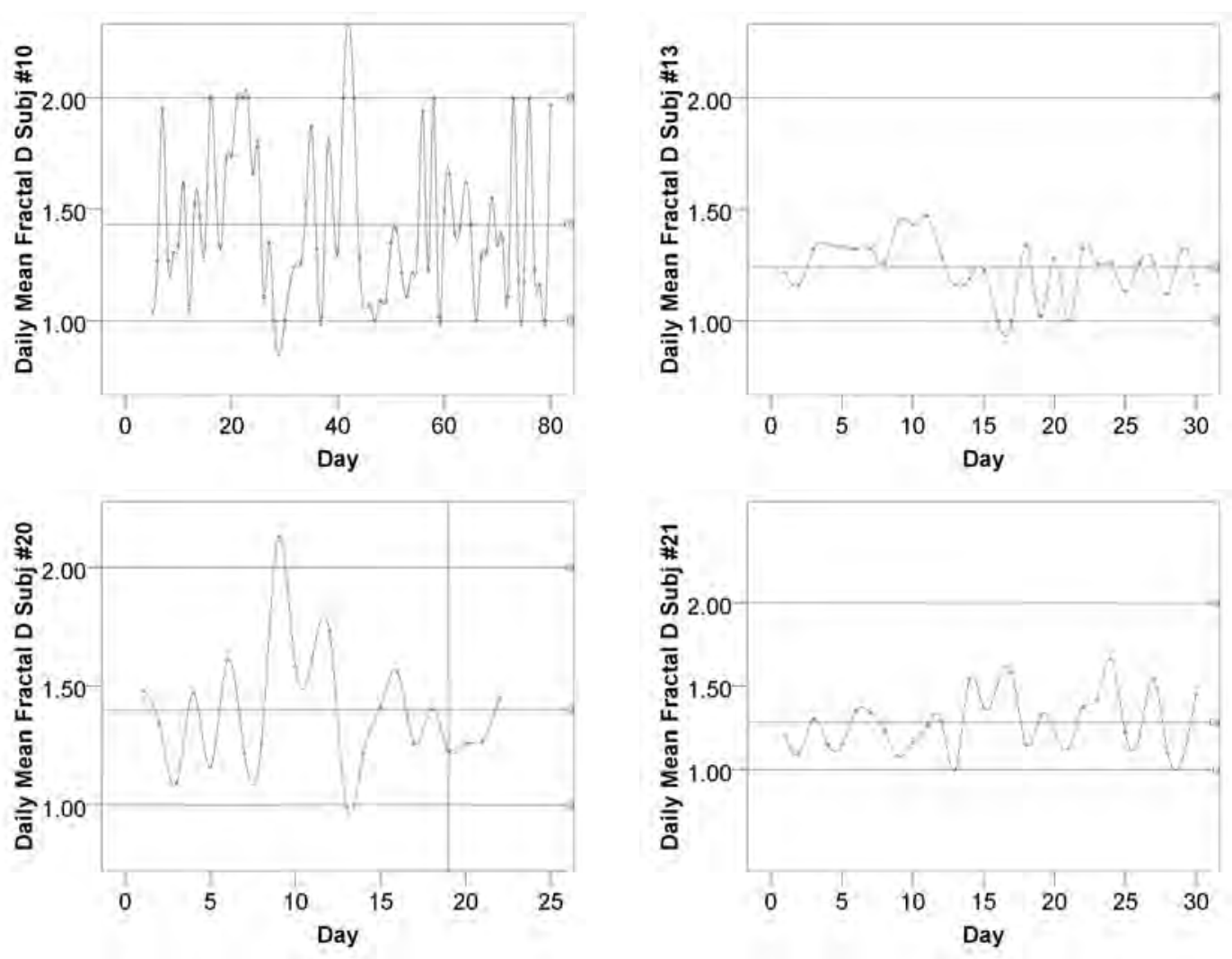

Figure 3. Top: Daily Fractal D variability for the same two subjects from ALF site \#1 using all data (the left panel represents 80 days, the right panel 30 days). Subject \#10 (top left) wore the tag for 80 days at which time she suffered a hip fracture. Top right: Subject \#12 had less variable daily Fractal D measures and wore the tag for 30 days with no falls. Lag 1 autocorrelations for subject \#10 and \#12 were .07 $(p=.54)$ and $.35(p<.05)$, respectively, with no other lags significant suggesting that subject \#10's movements represented a random process. The high level of day to day variability in subject \#10 suggests it may be predictive of her subsequent fall.

Bottom: Daily Fractal D for subject \#20 residing at a second ALF research site who fell after 18 days of wearing the tag. The vertical bar in each graph denotes the point in time the fall took place. Bottom right: Daily Fractal D for subject \#21 at the second ALF site who wore the tag for 30 days with no falls 
that led us to our current funded research examining changes in Fractal D preceding a fall.

\section{Discussion}

We have found in our researches that Fractal D tortuosity is relatively insensitive to either distance travelled or velocity, both of which failed to differentiate participants' MMSE. The MTS correlates negatively and significantly with subjects' MMSE scores independent of the subject's method of locomotion (wheelchair vs. walker vs. unassisted ambulation), suggesting Fractal D is sensitive to the underlying cognitive functions directing locomotion and MTS may permit quantification of cognitive contributions to fall risk even in individuals who cannot stand and can generate no SGB data. Since Fractal $\mathrm{D}$ can be assessed in less ambulatory individuals, it is highly relevant to the eventual development of fall prediction models in frail elderly. A practical advantage of MTS is that the 'path' is the unit of analysis and the MTS need only be located in areas routinely traversed by subjects, such as atriums, and not the entire ALF thereby reducing implementation costs. There are drawbacks to the MTS method; radio reflections introduce tracking inaccuracies, however, the technology underlying MTS has matured significantly through the introduction of three new versions and errors have decreased significantly. Furthermore, Fractal D is insensitive to small-scale random variations. UWB RFID systems must be precisely calibrated (often requiring laser rangefinders) in order to ensure accurate data, and the cost of the systems (approximately $\$ 7,000$ ) limits their availability to researchers.

Realization of an automated MTS to dynamically update Fractal D requires software development and implementation of several components. The first component calculates Fractal $D$ in realtime for each subject when a path is generated. The second component generates local reports of Fractal D levels for each participant for the benefit of ALF administrators interested in assessing fall risk.
A third component is the secure transfer of the information to offsite databases and electronic health records systems. In its final realization, we anticipate the MTS will be able to collect, analyze and distribute fall risk information automatically.

\section{Conclusion}

Jim Fozard's enthusiasm for our work comes in part from his longstanding interest in the possibilities of manipulating the environment to improve our adaptation to aging. This interest was described in a series of papers written with colleagues Popkin and Fisk $^{30,31}$ and fully developed and published in numerous articles in Gerontechnology. His starting point was human factors and ergonomics; he was active in developing the Technical Group on Aging and edited the first special issue on aging of the journal Human Factors ${ }^{31}$. There is a difference between Gerontechnology and the excellent body of work showing the complex interplay between environment and people as related to aging. Unquestionably the towering figure in this work is Powell Lawton ${ }^{32}$. Lawton argued that greater individual competence helped overcome challenges resulting from environmental press. The optimum state for an individual existed when competence was just high enough for environmental press to be stimulating but not overwhelming. As noted by Lawton in the Proceedings of the Second International Conference on Gerontechnology $^{33}$, we move beyond the limitations imposed by environmental press when we identify environmental interventions according to goals such as prevention, compensation, enhancement of quality of life, etc. Our current research employs unobtrusive location-aware technology to both identify and, in future, work automatically signal interventions for motor problems.

While I have characterized myself as the recipient of Jim's mentoring, I have learned that in gerontechnology, mentoring is necessarily a reciprocal process involving many people $^{34}$. When I volunteered to co-teach a seminar on environmental interventions and 
aging introduced by Professor Jim Fozard at the University of South Florida, I took the opportunity to introduce him to the multitudes of possibilities inherent in networked technologies used in various classes of communication systems ${ }^{35,36}$. This novel expo- sure opened his eyes to the prospects of expanded service coordination and delivery available through computer networks. I, in return, have received a broad education in human factors and aging from one of the true masters in the field.

\section{Acknowledgement}

The research was conducted at the University of South Florida Department of Aging and Mental Health at the College of Behavioral and Community Sciences with support from the federal Agency for Health Care Research and Quality under contract 1 R21 HS018205-01 'Evaluation and Integration of an Automatic Fall Prediction System'.

\section{References}

1. Stevens J, Corso P, Finkelstein E, Miller $\mathrm{T}$. The costs of fatal and non-fatal falls among older adults. Injury Prevention 2006;12(5):290-295; doi:10.1136/ ip. 2005.011015

2. Hornbrook M, Stevens V, Wingfield D, Hollis J, Greenlick M, Ory M. Preventing falls among community-dwelling older persons: Results from a randomized trial. The Gerontologist 1994;34:(1)16-23

3. Hausdorff J, Rios D, Edelberg H. Gait variability and fall risk in community-living older adults: A 1-year prospective study. Archives of Physical Medicine and Rehabilitation 2001;82(8):1050-1056; doi:10.1053/ apmr.2001.24893

4. Rizzo J, Friedkin R, Williams C, Nabors J, Acampora D, Tinetti M. Health care utilization and costs in a Medicare population by fall status. Medical Care 1998;36(8):1174

5. Vellas BJ, Wayne SJ, Romero LJ, Baumgartner R, Garry PJ. Fear of falling and restriction of mobility in elderly fallers. Age and Ageing 1997;26(3):189-193; doi:10.1093/ageing/26.3.189

6. Maki B. Gait changes in older adults: Predictors of falls or indicators of fear. Journal of the American Geriatric Society 1997;45(3):313-320

7. Condron J, Hill K, Physio G. Reliability and validity of a dual-task force platform assessment of balance performance: Effect of age, balance impairment, and cognitive task. Geriatrics 2002;50(1):157-162; doi:10.1046/j.1532-5415.2002.50022.x

8. Rubenstein L, Josephson K. Falls and their prevention in elderly people: What does the evidence show? Medical Clinics of North America 2006;90(5):807-824; doi:10.1016/j.mcna.2006.05.013
9. Hill K, Schwarz J, Flicker L, Carroll S. Falls among healthy, community-dwelling, older women: a prospective study of frequency, circumstances, consequences and prediction accuracy. Australian and New Zealand Journal of Public Health 1999;23(1):41-48; doi:10.1111/j.1467-842X.1999.tb01203.x

10. Hausdorff JM. Gait dynamics, fractals and falls: Finding meaning in the stride-to-stride fluctuations of human walking. Human Movement Science 2007;26(4):555-589; doi:10.1016/j.humov.2007.05.003

11. Herman T, Giladi N, Gurevich T, Hausdorff JM. Gait instability and fractal dynamics of older adults with a 'cautious' gait: Why do certain older adults walk fearfully? Gait \& Posture 2005;21(2):178-185; doi:10.1016/j. gaitpost.2004.01.014

12. French DD, Werner DC, Campbell RR, Powell-Cope GM, Nelson AL, Rubenstein LZ, Bulat T, Spehar AM. A multivariate fall risk assessment model for VHA nursing homes using the Minimum Data Set. Journal of the American Medical Directors Association 2007;8(2):115-122; doi:10.1016/j. jamda.2006.08.005

13. Fozard J. Speed of mental performance: The costs of age and the benefits of wisdom. In: Maletta GA, Pirozzolo FJ, editors, Advances in Neurogerontology. New York: Praeger; 1981; pp 59-96

14. Yogev-Seligmann G, Hausdorff JM, Giladi $\mathrm{N}$. The role of executive function and attention in gait. Movement Disorders 2008;23(3):329-342; doi:10.1002/ mds. 21720

15. Fozard JL, Heikkinen E. Maintaining movement ability in old age. In: Graafmans JAM, Taipale V, Charness NE, editors, Gerontechnology: A sustainable investment in the future. Amsterdam: IOS Press; 1998; pp 48-61

16. Fozard J, Gordon-Salant S. Aging and sensation and perception. In: Birren JE, Schaie KW, editors, Handbook of the Psychology of Aging. 5th edition. San Diego: Academic Press; 2001; pp 241-266

17. Cerella J, Poon LW, Fozard JL. Age and iconic readout. Journal of Gerontology 1982;37(2):197-202; doi:10.1093/ geronj/37.2.197 
18. Miller E. A note on visual information processing in presenile dementia: A preliminary report. British Journal of Social and Clinical Psychology 1977;16(1):99-100

19. Fozard J. Normal and pathological age differences in memory. In: Brocklehurst J, editor, Textbook of geriatric medicine and gerontology. 3rd edition. London: Churchill-Livingstone; 1985; pp 123-143

20. Kearns W, Moore D. RFID: A tool for measuring wandering in persons with dementia. In: Mihailidis A, Boger J, Kautz H, Normie L, editors, Technology and Aging: Selected Papers from the 2007 International Conference on Technology and Aging. Amsterdam: IOS Press; 2008; pp 154-164

21. Kearns W, Nams V, Fozard J. Wireless fractal estimation of tortuosity in movement paths related to cognitive impairment in assisted living facility residents. Methods of Information in Medicine 2010; in press

22. Hayes TL, Kaye JA, Pavel M. P2-225: A novel marker of mild cognitive impairment. Alzheimer's and Dementia 2006;2(3, Suppl. 1):S302

23. Pavel M, Hayes T, Tsay I, Erdogmus D, Paul A, Larimer $\mathrm{N}$, Jimison $\mathrm{H}$, Nutt J. Continuous assessment of gait velocity in Parkinson's disease from unobtrusive measurements: CNE '07. 3rd International IEEE/ EMBS Conference on Neural Engineering; 2007; pp 700-703

24. Rowe M, Lane S, Phipps C. CareWatch: A home monitoring system for use in homes of persons with cognitive impairment. Topics in Geriatric Rehabilitation 2007;23(1):3

25. Bose R, Helal A. Observing walking behavior of humans using distributed phenomenon detection and tracking mechanisms. SAINT 2008. International Symposium on Applications and the Internet; 2008; pp 405-408

26. Tyrer HW, Aud MA, Alexander G, Skubic M, Rantz M. Early detection of health changes in older adults. EMBS 2007; 29th Annual International Conference of the IEEE; 2007; pp 4045-4048

27. Kearns WD, Algase DL, Moore DH,
Ahmed S. Ultra wideband radio: A novel method for measuring wandering in persons with dementia. Gerontechnology 2008;7(1):48-57; doi:10.4017/ gt.2008.07.01.005.00

28. Crum RM, Anthony JC, Bassett SS, Folstein MF. Population-based norms for the MiniMental State Examination by age and educational level. JAMA 1993;269(18):23862391; doi:10.1001/jama.269.18.2386

29. Nams VO. Improving accuracy and precision in estimating fractal dimension of animal movement paths. Acta Biotheoretica 2006;54(1):1-11; doi:10.1007/s10441-0065954-8

30. Fozard J, Popkin S. Optimizing adult development: Ends and means of an applied psychology of aging. American Psychologist 1978;33(11):975-989; doi:10.1037/0003066X.33.11.975

31. Fozard JL. Changing person-environment relations in adulthood: Implications for human factors engineering. Human Factors 1981;23(1):7-27

32. Lawton M, Nahemow L. Ecology and the aging process. In: Eisdorfer C, Lawton MP, editors, The psychology of adult development and aging. Washington: American Psychological Association; 1973; pp 619674

33. Lawton MP. Future society and technology. In: Graafmans JAM, Taipale V, Charness $N E$, editors, Gerontechnology: A sustainable investment in the future. Amsterdam: IOS Press; 1998; pp 12-22

34. Bouma H, Fozard JL, Bronswijk JEMH van. Gerontechnology as a field of endeavour. Gerontechnology 2009;8(2):68-75; doi:10.4017/gt.2009.08.02.004.00

35. Kearns W, Fozard J. High-speed networking and embedded gerontechnologies. Gerontechnology 2007;6(3):135-146; doi:10.4017/gt.2007.06.03.003.00

36. Kearns W, Fozard J, Lamm R. How knowing who where and when can change healthcare delivery. In: Rocker C, editor, Smart Healthcare Applications and Services. Aachen: IGI Global; in review 